\title{
LAS FORMAS DE ORIENTACIÓN ESPACIAL DE LOS PESCADORES DE BUENAVENTURA, COLOMBIA
}

\section{SPATIAL ORIENTATION FORMS OF FISHERMEN BUENAVENTURA, COLOMBIA}

\author{
Armando Aroca Araújo ${ }^{1}$ \\ ${ }^{1}$ Licenciado en Matemáticas y Física. Magíster en Educación Matemática. Profesor Asistente, Universidad del Valle. aroca@ \\ etnomatematica.org
}

Rev. U.D.C.A Act. \& Div. Cient. 15(2): 457 - 465, 2012

\section{RESUMEN}

Se presentan algunos avances de una próxima publicación de un libro intitulado "Etnografía del saber matemático de los pescadores de Buenaventura. Pacífico colombiano". Aunque el propósito fundamental es mostrar las formas de ubicación espacial que emplean los pescadores antes y durante de sus faenas de pesca, en el análisis también se indican aproximaciones a otros procesos y pensamientos matemáticos, como el métrico y numérico, que emplea dicha comunidad.

Palabras clave: Orientación espacial, referentes naturales y artificiales de ubicación, configuración marina.

\section{SUMMARY}

Some progress in a forthcoming publication of a book entitled "Ethnography of mathematical knowledge of fishermen from Buenaventura. Colombian Pacific" is presented. Although, the main purpose is to display the forms of spatial location used by fishermen, before and during their fishing operations, the analysis also shows approaches to other processes and mathematical thoughts, as the metric and numerical, which is used by the community.

Key words: Spatial orientation, natural concerning location, artificial concerning location, marine settings.

\section{INTRODUCCIÓN}

Una historia lacónica de la llegada del afro colombiano hasta la creación del oficio de la pesca: La población afro colombiana, según Jaramillo (1969), provino de los pueblos de Guinea de la cuenca del Senegal, del Niger y del Sudán.
Desde allí fueron traídos, principalmente, al puerto de Cartagena, además de los de Santa Marta y de Riohacha. Luego fueron llevados por el río Magdalena, subidos por el río Cauca, hasta llegar a Santiago de Cali y Popayán. Se considera que los primeros africanos esclavizados tenían conocimientos en la metalurgia del hierro, el bronce y ganadería vacuna y no mucho, en la pesca. En el Nuevo Reino de Granada, parte de los pescadores eran los indígenas que habitaban la costa pacífica. Esos habilidosos pescadores, según Palacios (1989), eran pertenecientes a la familia lingüística de los caribes. El negro liberto aprendió no solo la habilidad de los indígenas para pescar, sino también los conceptos y las estrategias del español. Hubo, entonces, un mestizaje procedimental y conceptual.

Adaptando a Aprile-Gniset (2002), en 1878, las obras portuarias o ferroviarias en Buenaventura crearían la clase trabajadora, conformada por afro colombianos y se configuró un mapa más complejo de oficios, cada uno con formas de analizar, razonar o abstraer diferentes, con técnicas y herramientas diversas. Esto trajo, en aquel tiempo, migraciones y varios se dispersarían en diversos oficios, creándolos a partir del entorno social, cultural o geográfico y optimizarían otros de conocimiento sea personal o comunitario, entre ellos la misma pesca. Interpretando a Lunkes (2004), Machado et al. (2004), François \& Kerkhove (2010), D’Ambrosio (2011), ésto, implicaría soluciones de problemas, de invención, de fantasía y de imaginación, de adaptación o implementación de herramientas, de procesos de razonamiento y abstracción que las anteceden, de creación de técnicas para hacer el menor esfuerzo y de creación de palabras para acciones o referirse a nuevos sustantivos, nacerían así nuevas etnomatemáticas. La etnomatemática del pescador del pacífico colombiano.

Los pescadores, al tener como reto la captura de diferentes peces marinos y marisco con conchas, codificaron 
el mar para este propósito. Pues fue la captura de las diversas especies que les impondría los retos de ubicarse, espacialmente, para no perderse. Entonces, la comunidad paulatinamente codificó el mar y creó su propia realidad, tal como lo plantea Berger (1993). Si las prácticas y saberes individuales o colectivos que iban apareciendo como producto de la resolución de problemas eran óptimas para la comunidad, se instalaban hasta que una mejor técnica o tecnología surgiera.

En el intercambio cultural, habrán aprendido de los indígenas cuáles serían las mejores maderas para elaborar canoas o potrillos y los canaletes o remos. Bastaría que un solo individuo observara, experimentara y luego reprodujera, desarrollando la experticia, que después la comunidad reconocería. Habrán aprendido las primeras formas de pescar y aprovecharían las técnicas, la simulación o adaptación de la tecnología utilizadas por los españoles. Sin duda, un individuo tendría la idea de cuestionar algunos métodos y propondría otros. Al ir progresivamente entrando en las profundidades del mar y en trayectos mayores a un día, harían mechones para ir alumbrando en las noches; entenderían el comportamiento del mar, se darían cuenta que si tiraban la red en cierta profundidad solo atrapaban ciertos peces; que podrían seguir pescando, sin estar presentes, con anzuelos si los dejaban flotando o anclados, o tirando trasmallos que quedarían a merced de la corriente del mar. Verían, cada vez que las nubes lo permitieran, pues estaban en la región más lluviosa del país y una de las principales a nivel mundial, algunas estrellas que salen de tal parte y se mueven hacia cierto sitio y le asignarían, entonces, un referente de orientación, como lo harían con el sol, la luna y las estrellas. Se percatarían que el mar siempre tiene una ola que los empuja hacia las orillas y que cuando la lancha la toma de frente parece como si chocara contra ella cada dos segundos y la proa se levanta, pero que si se coloca a favor sentirían un deslizamiento pausado y tranquilo; sin embargo, también conocerían que es mar afuera esta dirección a veces es caótica y se necesitaría mucha experticia, o sea, la práctica, para poder leer las olas y saber cuál manda a tierra. Advertirían la necesidad de interpretar muy bien los nubarrones que son típicos y únicos de esta parte del mundo. Codificarían, de igual manera, las diversas direcciones del viento. Notarían que la marea cada tantos días se comporta de una manera y que para salir en lancha hacia mar afuera tomarían la séptima ola y tomando así el impulso del mar. Comprenderían, progresivamente, cuatro dimensiones para la orientación. Delimitarían sus rutas de navegación por las redes, los cabos y trasmallos, las boyas, las rutas comerciales, la basura flotante, las luces artificiales y los buques, hasta poder crear un oficio con una diversidad de estrategias, de técnicas, de herramientas y de lenguaje muy ricos.

\section{MATERIALES Y MÉTODOS}

Esta investigación, se desarrolló en el marco del Seminario de Formación en Etnomatemáticas, que se oferta en la Universidad del Valle, con sedes en Buenaventura y Cali. Fueron en total dos visitas colectivas, en compañía de estudiantes y más de veinte personales, que se realizaron desde el periodo 2010A hasta el 2012A. La investigación tuvo en cuenta, tal como se hizo en Rey \& Aroca (2011), en Goetz \& LeCompte (1998), más en Deslauriers (2005) y en Campos (1995). Por ello, se empleó una metodología que admitiera la utilización de una pluralidad de instrumentos, como entrevistas, grabaciones, fotos digitales, apuntes de campo, para comprender lo mejor posible las prácticas y los saberes de los pescadores. Fueron más de 30 entrevistas estructuradas. Estas entrevistas constaban de tres categorías de análisis, más las respectivas preguntas asociadas, entre ellas, condiciones socio-económicas de vida, sistema cultural, procesos relacionados con la actividad de la pesca y otras actividades económicas. También, se aplicó la metodología propuesta en Aroca (2008), concerniente a investigaciones desarrolladas en el marco de la descripción y el análisis de una etnomatemática. Por otro lado, se tuvo en cuenta investigaciones cuyos objetos de estudio eran similares o directamente relacionados, como los realizados por Goetzfridt (2008), quien analizó sistemas de numeración, de conteo, de medición, de clasificación, de relaciones espaciales, de simetría y de geometría, entre otros temas, de habitantes de las regiones de la Polinesia, Melanesia y Micronesia; De Vega (2005), quien analizó el sistema de navegación desarrollado por los aborígenes de Polinesia, estos dos últimos autores hicieron sus investigaciones en las costas del pacífico australiano. Chieus (2009), después de un preámbulo teórico significativo, analizó la construcción de redes de pesca de los caiçaras, que habitan la ciudad de Ubatuba, en el litoral norte paulista; Diegues (2004) planteó cómo la actividad de caza a gran escala conlleva a la conformación de comunidades humanas y Campos (1982) analizó algunas prácticas y saberes de los habitantes de la isla de los Búzios; estos tres últimos autores investigaron en costas de Brasil y aportarían para el análisis de los objetos de estudio de esta investigación.

\section{RESULTADOS Y DISCUSIÓN}

El pescador tiene en cuenta cuatro dimensiones para orientarse. La figura 1 muestra cómo se encuentra inserto el pescador en esta configuración de su entorno. La dimensión 1 , corresponde a la celestial o superior, que es infinita, en donde existen tres referentes universales para la orientación: el movimiento y las fases de la luna, el movimiento de las estrellas y la traslación y la rotación de la tierra en torno al sol; a esto, Campos (1982), lo llamó "relojes" naturales. La dimensión 2, corresponde a la atmosférica, que es local 
o regional, pues las nubes, los aguaceros, los rayos y los vientos tienen comportamientos disimiles, según la región del mundo y tienen simbolizaciones contextualizadas, por ejemplo, que el viento del norte viene de tal lugar y conduce a otro. La dimensión 3, corresponde a la superficie del mar, donde se mezclan referentes naturales que son mundiales y otros que son simbólica o comercialmente locales; en esta dimensión, se encuentran las olas, el color del mar que, para el caso de Buenaventura, se pueden encontrar hasta cinco tonos, como marrón, amarillo, verde, azul y "tirando" a negro, como producto de las desembocaduras de ríos; las corrientes, las rutas comerciales, las basuras flotantes, los cabos, los riscos o arrecifes, los trasmallos, las boyas, las orillas, las costas, los referentes costeros naturales o artificiales, como los árboles, las montañas, el faro, las luces de caseríos, los islotes, las bocanas o esteros. La dimensión 4 es la profundidad del mar que también es local, que permite, usando el sondeo, determinar cuán lejos puede estar de la orilla y qué peces puede hallar en ese momento, como también establecer bancos de arena, riscos o pequeños arrecifes y sedimentos o basura que depositan los ríos.

El concepto de distancia: Una percepción tridimensional: El concepto más importante cuando se "marca el rumbo", para salir a pescar, es el de la distancia. Cuando a los pescadores se les interroga por distancias recorridas ellos hablan de brazas. Un ejemplo, a varios de ellos se les hizo la siguiente pregunta: ¿qué tan lejos ha llegado usted? Y algunas de las respuestas fueron a 3, 5, 10, 15, 30 brazas. Una braza es la longitud que hay de una mano a otra con los brazos extendidos, algunos consideran que es de dos metros y la mayoría de metro y medio, tal como lo plantean los pescadores de Brasil, descritos en Chieus (2009). Nuestra lógica, haría el cálculo de multiplicar el número de brazas por dos y daría distancias de recorrido muy pequeñas, pero un pescador manifestó que no se trataba de hacerlo así, sino de la profundidad. Aquí hay otra lógica de cálculo. En topología habría una similitud, pues daría la sensación que se trata de la distancia de un punto a un conjunto infinito de puntos, pero en este contexto, no se piensa en la linealidad sino en la profundidad y de manera funcional, porque se trata de capturar ciertos peces o mariscos con concha. En este sentido, la distancia marítima implica:

1. No va de un punto a otro punto. Va de un punto a una región que no es única, es decir, la misma región puede estar en otra parte del mar, debido a la irregularidad del fondo, tal como lo muestra la figura 2a. Pero también dicha región de fondeo podría estar fraccionada, según la figura $2 b$.

2. Va de un punto que, en general, está en la playa, a infinitas fracciones del mar, pero se tiene en cuenta, fundamentalmente, la profundidad de esta y el pez o marisco con concha, que habita en esa zona. De manera simbólica, sería $\mathrm{D}=f(p, \infty)$; donde $\mathrm{D}$ es la distancia recorrida en la superficie del mar, $p$ la profundidad y $\leftrightarrow$ el pez o marisco con concha que se quiere capturar.

3. El cálculo parte desde la profundidad del mar, va a su superficie que evoca regiones conocidas y, luego, se proyecta a la playa, o viceversa: cálculo en ELE. Pero cuando se está en altamar, el cálculo hasta la playa se

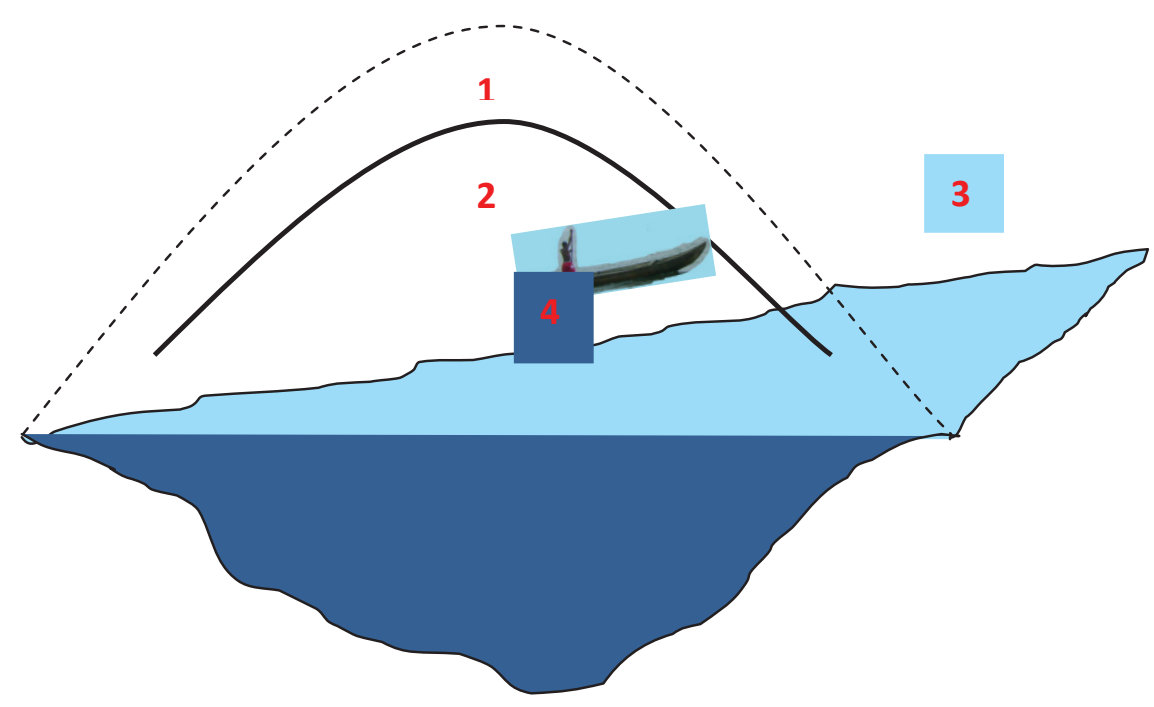

Figura 1. Inserción del pescador en cuatro dimensiones, espaciales y planas, que le sirven para su orientación. 1. Dimensión celestial (las estrellas, el sol y la luna); 2. Dimensión atmosférica (vientos y nubes, relámpagos, oscurana y tormenta); 3. Dimensión superficial (boyas, redes, montañas, color del mar, el sonido de las olas, los puntos de pesca, candelilla, árboles, olas, basuras flotantes, corrientes, pájaros y otros) y 4. Dimensión profundidad (las pozas, lo seco y lo hondo, las pegasrocas filosas y palos enterrados y bancos de arena que se reflejan en la superficie del mar). 
hace en unidades de tiempo, de distancia superficial o por medio de la fuerza del viento.

El sondeo es lo que finaliza la noción de medida playa $\rightarrow$ mar afuera, si el cálculo se origina desde la playa y, en algunas circunstancias, será el viento si el cálculo se hace mar afuera $\rightarrow$ playa.

Términos o expresiones que indican concepciones espaciales, métricas o numéricas: En la dimensión de profundidad, la braza es uno de los conceptos más importantes en la pesca. Lo interesante es cómo relacionan las brazas con el tiempo de ruta; por ejemplo, algunos pescadores establecieron que 10 brazas equivalen a 20 minutos. Esta relación se genera por el consumo de gasolina que tienen los motores fuera de borda, de no tener control en esto quedarían a la deriva. Estos casos tendrían implicaciones diferentes a las planteadas en el concepto de distancia, pues se involucra el tiempo. La braza también se relaciona con el sondeo. La sonda es un instrumento artesanal, que sirve para medir el fondo del mar y es basada en una piola de nylon y una plomada amarrada en uno de sus extremos. Sondear, entonces, es tirar la plomada al mar y medir su profundidad recogiendo la piola y midiéndola en brazas. En cuanto a la dimensión atmosférica, el mal tiempo es cuando se avecina un fuerte aguacero, mucho viento que pica al mar y la oscurana o el tiempo duro, consiste en la alta concentración de nubes o un fuerte aguacero, tronamenta y oscurana, que implica que no se puede observar en ninguna dirección; en estas condiciones cuando cae un rayo, el pescador se encandila y se puede desorientar.

Los siguientes referentes de orientación, naturales [RN] y artificiales [RA], están dispersos en las cuatros dimensiones espaciales o planas. Están distribuidas así: celestial [solo RN], atmosférica [solo RN], superficial [RN y RA] y profundidad [solo RN]. Esto implica que la comunidad de pescadores le dio mayor simbolismo a la superficie que a las otras tres dimensiones, contrario a lo que se podría pensar que fuese la celestial o superior, pues la historia "universal" nos ha educado que los pescadores, fundamentalmente, se orientaban por las estrellas, pero eso, en una de las zonas más lluviosas del mundo, no es así.

\section{Referentes naturales:}

El sol, traslación de la tierra en torno a él. Movimiento y fases de la luna. Movimiento de las estrellas: La simbología otorgada al sol orienta a los pescadores, porque tiene un punto de "salida" y otro de "llegada", relativos a lugares conocidos. En Campos (1999), se puede ver más detalles del papel de orientación del astro rey, que le han asignado en diversas culturas, como por ejemplo, lo descrito por Campos (1982), de cómo los habitantes de las Islas de Búzios, en Buenaventura y en toda la región costera del pacífico colombiano toman el comportamiento de la luna y

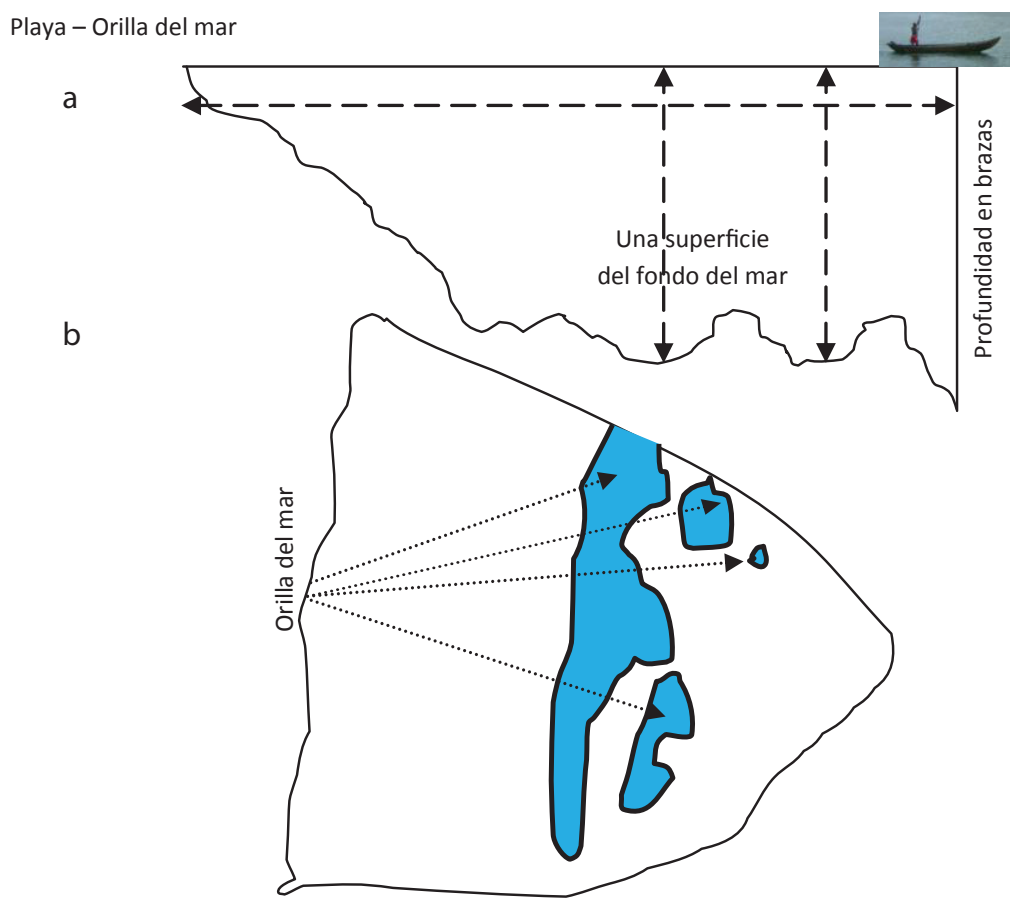

Figura 2: a) Percepción tridimensional del concepto de distancia marítima a partir de las Brazas. b) Ejemplo de varias regiones que podrían representar la misma cantidad de brazas en profundidad. 
del sol para iniciar sus faenas de pescas; además de esto, lo esencial es cómo estén los "tiempos" o las "aguas", que es una mezcla de tipo de mareas subiendo o bajando, número de días en puja o quiebra, lluvias, oscurana, tronamenta, relámpagos y vientos. Es fácil ver, entonces, a un pescador indicando con sus brazos la trayectoria del sol y trazarse un mapa mental que le permite orientarse con respecto a otros corregimientos. Además, que le sirve de reloj para hacer retornos o calado y recogida de trasmallos o cabos.

La luna tiene un comportamiento similar al del sol, solo que ésta juega su papel en determinadas horas, al igual que las estrellas. La luz de la luna ilumina y permite ver formas en las orillas que pueden ser reconocidas. Ver su trayectoria también indica una configuración del cielo, que tiene repercusiones en la construcción de un mapa mental, que se valida en la interpretación de la superficie, es decir, cuando el pescador mira para el cielo, sea a las estrellas, al sol o a la luna, si las nubes o la lluvia se lo permiten y mira sus movimientos o trayectorias está pensando en cómo están ubicados algunos lugares o referentes en la tierra. Mira para el cielo, pero piensa en la tierra. Fundamentalmente, la luz de la luna sirve cuando está en luna llena y cuando es así, permite ver claramente las orillas. Cuando hay menguante, es decir, ausencia de la luna, es mejor para la pesca. La relación que hay de la luna con el mar, es que de ella depende el comportamiento de las mareas y tiene implicaciones en cuanto al zarpe y arribo a diversos lugares.

Las olas o corrientes: Algunos pescadores piensan que para la orientación es más importante la ola que el viento, pero la mayoría piensa lo contrario. El mar tiene un único movimiento que es el mar de leva y él siempre empuja hacia la orilla. Según ellos, la ola de leva se encuentra a unas seis brazas de profundidad. Unos pescadores manifestaron que, en caso tal si se llegasen a desorientar, pues nunca se pierden, entonces apagan los motores y dejan que el mar de leva actúe y gire la lancha, quedando la proa apuntando hacia la orilla, prenden motores y trazan rumbo, que tiende a ser lineal, pues ir haciendo curvas la lancha se podría voltear. "Es mejor de frente, es mejor ir rompiendo la ola"; sin embargo, algunos pescadores hablaron del copeteo_de olas, que es cuando no se puede ver la ola de leva y hay desorden de las olas y solo un pescador muy práctico la puede identificar, de lo contrario, se desorientan si solo dependen de esto. Ciertos pescadores salen a faena a pescar por varios días consecutivos cuando la marea está baja, porque se les facilita su salida y retornan cuando la marea está subiendo, así tienen la corriente a su favor. En estos fenómenos de cambio de marea, por ejemplo, en puja, se da cuando sol, luna y tierra están alineados, es decir, crece el nivel del agua. Y si es quiebra sol y luna ejercen fuerzas en direcciones diferentes sobre la tierra, baja el nivel del agua. Estos fenómenos son más visibles en la Costa del Pacífico que en la costa del Caribe colombiano, debido a su profundidad. En la figura 3a, se muestra una lancha de viento y marea, que quedó encallada en la Bocana cuando bajó la marea y en la figura 3b, se muestran las adaptaciones arquitectónicas para enfrentar el comportamiento de la marea. Ahora, cqué relación tiene la puja y la quiebra con la orientación? Según varios pescadores cuando el mar está en puja puede subir alrededor de cinco brazas y, en quiebra, entre dos brazas, entonces, eso les permiten a ellos poder determinar qué tipo de peces pueden salir a buscar y qué sectores quedarían con determinada profundidad. A más de esto existe una clasificación de las aguas, entre buenas y malas, porque los pescadores llevan las cuentas o fechas de la marea, que consiste en lo siguiente. La puja y la quiebra duran, cada una, ocho días y cuando empieza la puja se inicia la pesca, que debe durar la misma cantidad de días hasta el primer día de la quiebra. Si algún pescador no tiene las cuentas, entonces, se la pregunta a otros de su confianza. Otros pescadore s consideran que el mejor comportamiento del mar para pescar es la puja pequeña, porque en la puja grande pueden pescar hasta tres días consecutivos, en cambio en la puja pequeña hasta cinco. Cuando la puja es muy fuerte no es conveniente hacerlo porque la corriente submarina es tan fuerte que rompe el nylon de los trasmallos.

\section{Los Vientos:}

"Cuando los vientos son para arriba el mar corre para abajo y cuando los vientos son para abajo el mar corree para arriba".

Palabras de un pescador de Punta Soldado

La mayoría absoluta de los pescadores coinciden en que los vientos son los que los ayudarían a orientarse, en caso tal de perder el rumbo. El viento, además, dependiendo de su intensidad, que se siente en el cuerpo, es relacionado con la distancia que habría desde la embarcación con la orilla; por ejemplo, si el viento pega muy fuerte, entonces, se está muy alejado de la orilla o del pueblo y si pega suave se está relativamente cerca de la costa. Se ha dicho que cuando se les pregunta a los pescadores que es lo más lejos que han llegado, ellos responden con brazas, o sea, la respuesta es con respecto a la profundidad, pero cuando se está en el mar, hablan de distancia superficial y lo que hay es un cálculo subjetivo, a partir de la percepción del comportamiento atmosférico o celestial. Es probable que exista una especie de relación biunívoca entre la intensidad del viento, que va variando con magnitudes de distancias específicas, no estrictamente hablando de una relación uno a uno, sino una relación de percepción-presión en el cuerpo de la intensidad del viento, con distancias superficiales. Aquí, sin duda alguna, la experiencia que ellos llaman la práctica y la memoria son los procesos cognoscitivos que les permite codificar la profundidad y la superficie del mar, su espacio aéreo y su entorno físico-visual y perceptivo. 

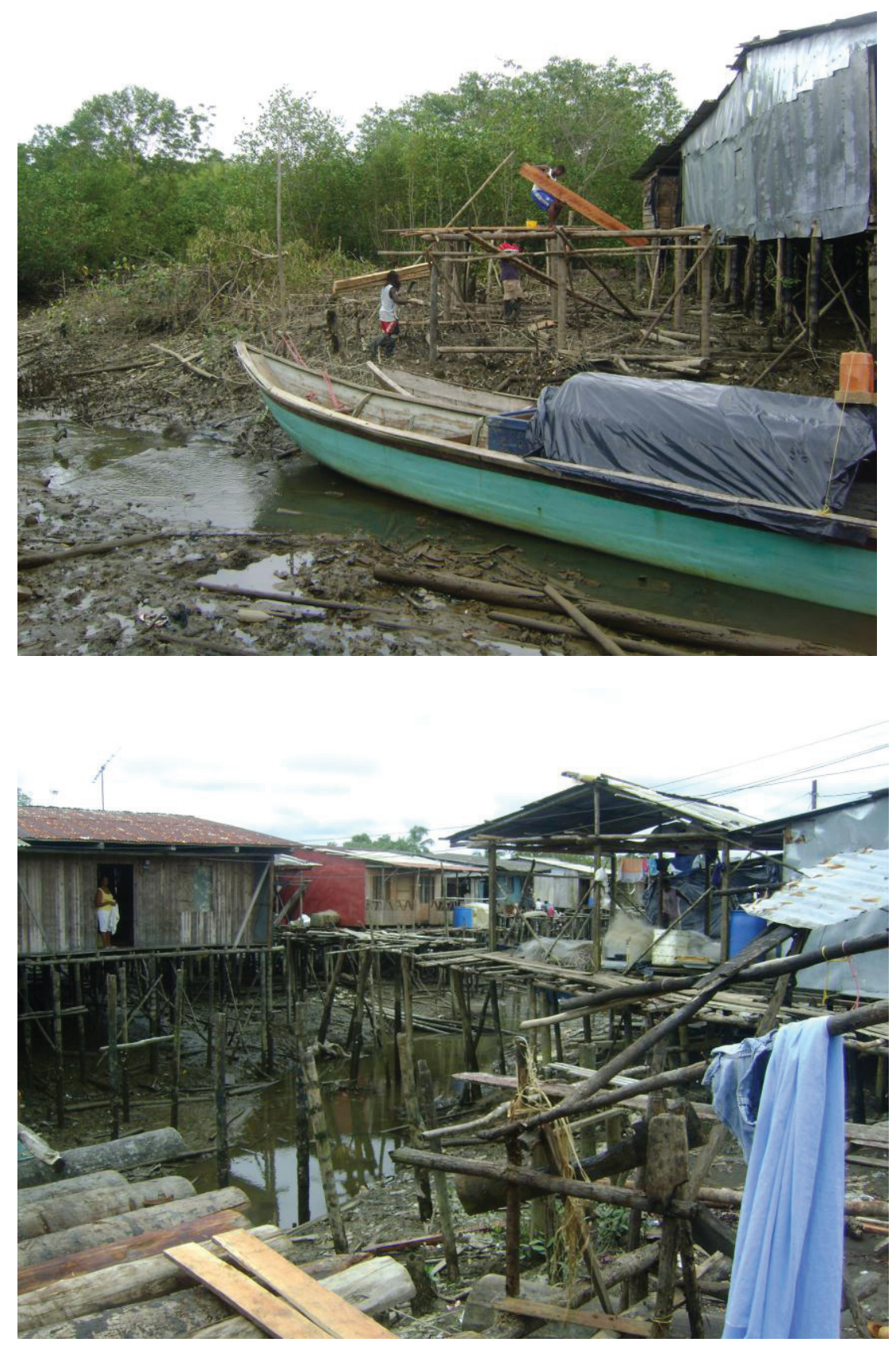

Figura 3: a) Lanchas que quedaron encalladas cuando el mar entró en quiebra; b) Arquitectura de la Bocana para afrontar los cambios de la marea, sector residencial donde no llegan los turistas.

Algunos pescadores consideran que existen cuatro vientos, otros consideran que ocho y, tal vez, cada grupo tiene la razón, pues es su propia simbología, en este caso no comunitario sino grupal, estos vientos serían el del Norte, el del Sur, el del Este, el del Sureste, el del Suroeste, el del Noreste y el del Noroeste. Todos consideran que el viento del Norte es el que "manda pa' fuera" y el viento del Sur los "trae pa' tierra". En esto no hubo discrepancia, pues otros pescadores consideran que el viento del Este, al igual que el del Norte, también manda pa' fuera y que el viento del Oeste también manda pa' tierra. Consideran que cuando el viento sopla desde el noroeste la "marea está alta" y cuando sopla desde el sur, este o sureste la pesca es permitida, pero se ha dicho que en todo esto hay relatividad, pues estas direcciones también tienen asociaciones simbólicas que dependen del lugar donde está ubicado el caserío o corregimiento. Dado que el viento se opone al movimiento, él puede repercutir 
en que el desplazamiento sea más rápido o lento, tanto si la lancha es de canalete o de motor. Los vientos, según algunos pescadores, influyen en la dirección y en la fuerza de las corrientes y pueden formar la marejada, conllevando esto a que las embarcaciones tomen rumbos distintos. La figura 4 muestra una representación que hizo un pescador de Buenaventura, donde al hacer la representación de la dirección de los vientos no siempre coincide con la realidad.

Las costas o playas: Una playa puede ser sinónimo de caserío o de un sitio turístico, en consecuencia, si se llegaban a desorientar y la embarcación llegase a una playa, entonces, se podía encontrar un lugar de referencia para luego trazar rumbo. Las costas están llenas de accidentes geográficos que permiten ubicarse y reconocer sectores, profundidades y las simbolizaciones de cada estero, bocanas, salientes, cerros o bajos, que es la parte rocosa e inferior de cerros o peñascos, donde las olas chocan y generan particulares sonidos, con los cuales, se orientan en las noches, salientes o cerros.

Se concluye que los pescadores usan cuatro sentidos para orientarse: la vista, por obvias razones; huelen la lluvia, que no es el mismo olor que se siente en tierra, "viene la oscurana o mal tiempo". Escuchan por las noches los golpes de las olas y cambian el rumbo de navegación o se alejan de dicho sector. Sienten en el cuerpo, en el rostro, en los brazos, en la espalda y en el abdomen la dirección del viento. ¿̇os citadinos cuántos sentidos usamos para la orientación?
En las costas, se encuentran los esteros, que son la desembocadura de "agua de adentro", por lo general, agua dulce y cada estero puede tener un referente de una localidad o viviendas. En un recorrido largo, se pueden ver varios esteros y lo que hacen los pescadores es contarlos mentalmente cuando es necesario y saben, entonces, cuántos hay de una localidad a otra, es como pensar cuántas cuadras hay de una casa a otra casa.

En las costas, las montañas definen formas con características singulares que son reconocibles o existe un conjunto de pequeñas montañas o árboles que están en las orillas, que configuran un referente natural de orientación inconfundible. Las montañas, los cerros o algunos árboles son un gran referente en el día, pues se pueden observar desde muy lejos, mientras la curvatura de la tierra lo permita. Sirven también para establecer desvíos, pues dependiendo de los cerros puede haber corrientes fuertes o bancos de arena que son mejor esquivar o pasar con baja velocidad a motor.

El papel de las nubes: Ellas juegan un gran papel, pero en la desorientación, pues cuando se aproxima una oscurana, se pierden los referentes, tantos naturales como artificiales y peor aún, cuando llegan acompañas de vientos. Salvo el caso que el mal tiempo sea divisado a tiempo y se pueda cambiar el rumbo, pero esto sucede en raras ocasiones. En

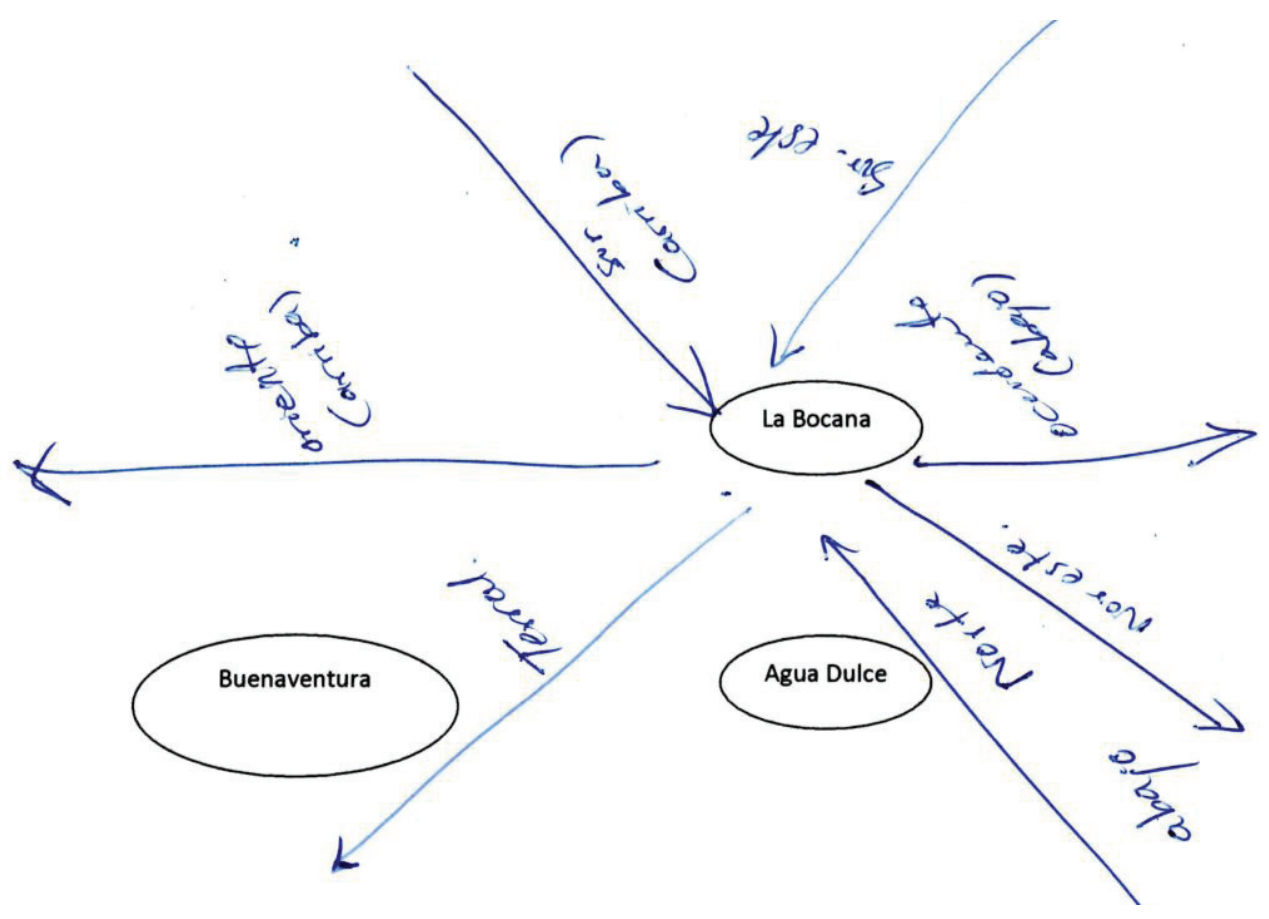

Figura 4. Representación de las direcciones de los vientos según un pescador de Buenaventura. 
el pacífico colombiano casi a diario llueve y estos aguaceros no son tan sencillos de esquivar. Estas tempestades pueden generar turbulencias en el mar y pueden llegar a romper los trasmallos; no obstante, en las palabras de un pescador estaría la razón de no poderlos evitar a tiempo: "si pensáramos en el mal tiempo entonces nunca saldríamos a pescar". En algunos casos de días nublados, no se puede observar hacia los alrededores referentes distintos al mar y las nubes, pues ellas formar una barrera circular de $360^{\circ}$.

El rayo, también juega un papel en la desorientación o desconcentración; cuando cae un rayo en el mar encandila más de lo habitual que si sucediera en tierra, según ellos, el rayo alumbra demasiado, porque el mar lo refleja mucho y la visión se oscurece demasiado, esto implica que mientras la pupila se vuelve a dilatar se puede perder el rumbo, pues si la lancha es a motor, tal vez haga un giro, por la falta de control. El rayo es lo más temido por los pescadores, pues creen que sus cabezas son buscadas por éstos.

\section{Referentes artificiales}

A algunos objetos o avances tecnológicos, los pescadores le han otorgado simbología o funcionalidad. Entre ellos, se encuentran las luces del Puerto de Buenaventura, de las casas, de los caseríos o de los buques, las cuales, no fueron diseñadas para codificar el mar. En cambio, la luz del faro sí fue concebida para orientar, es decir, tiene funcionalidad directa, al igual que las luces titilantes y nocturnas de las boyas: azules y rojas. También, existen otros artefactos que ayudan, en menor proporción, para que el pescador se oriente, como la brújula, usada por pocos, el radio teléfono o el celular.

Los colores de las boyas le indican tipos de profundidades a las tripulaciones de los barcos comerciales que llegan a Puerto, desde diferentes países, pero los pescadores artesanales también las utilizan para orientarse cuando las pueden ver. Ellos le han asignado representación propia al color de las boyas. La boya azul es mar profundo y su opuesta es la roja, la amarilla indica la entrada al puerto y la verde que se puede pescar tranquilamente. Ciertos pescadores informaron que la boya azul les servía de orientación cuando querían ir "pa arriba", por ejemplo, a Nuquí o si querían ir "pa abajo", el sur, para Nariño.

Desde el puerto de Buenaventura zarpan a cada momento lanchas, adscritas a diferentes empresas de transporte de pasajeros, de turistas o mercancía. La cuestión es que estas lanchas, más grandes que las usadas en la pesca artesanal, tienen unas rutas muy concretas, "tienen sus propios caminos", es decir, contribuyen a la codificación de la superficie del mar, como zona de navegación; esto implica que los pescadores saben que en estos trayectos sociogeográficos no pueden tirar sus trasmallos o cabos o, de igual manera, quedarse anclados, porque podría suceder un accidente. Esto lo podrían hacer en horas de la noche, cuando cesa esta actividad.

Por lo general, los pescadores dejan por varias horas sus redes en el mar, sea el trasmallo o el cabo y ellas quedan flotando, codificando así la superficie de tránsito.

La sonda es otro referente artificial de orientación, pues en la práctica los pescadores lo que hacen es tirarla y toman la medida, por ejemplo, 20 brazas; luego avanzan y, si es menor la medida o "marca seco", entonces, según ellos, "van bien", van para una orilla; pero si la medida es mayor, van para mar afuera. Este mecanismo se usa cuando están en mar abierto sin poder ver nada a su alrededor, solo mar y cielo, acompañado del zumbido intenso del viento o cuando quedan atrapados por una oscurana.

A manera de conclusión, se podrían ver diversas situaciones. La primera que, una vez más, se valida que el pensamiento matemático es cultural y son muchos tipos diferentes de pensamientos matemáticos. En consecuencia, no hay una sola matemática, se podría, incluso, decir que existen tantas matemáticas como grupos culturales o sociales diferenciados existan. La segunda es el análisis de los posibles aportes que hacen este tipo de matemáticas a la educación matemática. Por ejemplo, ćcuál es la relación del desarrollo del pensamiento métrico y espacial escolar con la cotidianidad de los niños y de las niñas?, ċcómo la enseñanza del Sistema Métrico Decimal puede dar cuenta de estos conocimientos?, ¿de qué manera el profesor de matemáticas enfrenta este tipo de situaciones a-didácticas, en particular, la relación disyunta que existe entre las formas de ubicación espacial urbana que está dada por calles, por carreras, por avenidas y la forma de ubicación espacial marina, dada por vientos, por sondeos, por movimientos de astros, entre otros?

Agradecimientos: A los pescadores de Buenaventura, la Bocana y Punta Soldado y a la Universidad del Valle. Conflicto de intereses: El manuscrito fue preparado y revisado por el autor, quien declara ser el único autor y que no existe ningún conflicto de intereses que ponga en riesgo la validez de los resultados presentados. Financiación: Los costos personales estuvieron a cargo del autor, mientras que una de las dos visitas colectivas se hizo con ayuda de la Universidad del Valle, la otra fue con recursos propios de los estudiantes, de la sede de Buenaventura.

\section{BIBLIOGRAFÍA}

1. APRILE-GNISET, J. 2002. Génesis de Buenaventura. Universidad del Pacífico - Buenaventura. Artes gráficas del Valle. Cali. 534p. 
2. AROCA, A. 2008. Una propuesta metodológica en etnomatemáticas. Rev. U.D.C.A. Act. \& Div. Cient. 11(1):67-76.

3. BERGER, P. 1993. La construcción social de la realidad. Ed. Amorrortu editores. (Argentina). 233p.

4. CAMPOS, M. 1999. SULearvs NORTEar: Representações e apropriações do espaço entre emoção, empiria e ideología. Programa de Estudos Interdisciplinares de Comunidades e Ecologia Social. EICOS - Instituto de Psicologia - UFRJ/UNESCO. Disponible desde Internet en: http://www.sulear.com.br/texto03.pdf (con acceso 14/09/2011)

5. CAMPOS, M. 1995. Sociedades e Natureza: Da etnociência à etnografia de saberes e técnicas. Disponible desde internet en http://www.sulear.com. br/texto04.pdf (con acceso 15/11/11).

6. CAMPOS, M. 1982. Saber mágico, Saber Empírico e outros Saberes na llhas dos Búzios. En: A. Eulalio. (Org.). Caminhos cruzados. Linguagem, Antropologia e Ciências Naturais. Brasil: Ed. Brasiliense S.A. p.23-32.

7. CHIEUS, G. 2009. A braça da rede, uma técnica caiçara de medir. Rev. Latinoam. Etnomat. 2(2):4-17.

8. D'AMBROSIO, U. 2011. Uma Síntese Sociocultural da Historia da Matematica. Ed. PROEM. (Brasil). 96p.

9. DESLAURIERS, J. 2005. Investigación cualitativa. Guía práctica. $2^{\text {a }}$ Edi. Papiro. (Colombia). 143p.

10. DE VEGA, M. 2005. El arte de navegar de los polinesios. Disponible desde internet en: http://www.wikilearning. com/articulo/el_arte_de_navegar_de_los_polinesiosel_arte_de_navegar_de_los_polinesios/7301-1 (con acceso 20/10/2011).

11. DIEGUES, C. 2004. A Pesca Construindo Sociedades Ed. NUPAUB-USP. (Brasil). 315p.
12. FRANÇOIS, K.;KERKHOVE, B.2010.Ethnomathematics and the philosophy of mathematics (education). En: Löwe, B.; Müller, T. (eds.) PhiMSAMP. Philosophy of Mathematics: Sociological Aspects and Mathematical Practice. Ed. College Publications. (London). p.121154.

13. GOETZ, J.; LeCOMPTE, M. 1998. Etnografía y Diseño Cualitativo en investigación educativa. Ed. Morata. (Madrid). 280p.

14. GOETZFRIDT, N. 2008. Pacific Ethnomathematics. A Bibliographic Study. Ed. University of Hawaii Press (Honolulu). 319p.

15. JARAMILLO, J. 1969. La controversia jurídica y filosófica librada en la Nueva Granada en torno a la liberación de los esclavos y la importancia económica-social de la esclavitud en el siglo XVIII. Rev. An. Col. Hist. Soc. Cult.. 4:63-86.

16. LUNKES, A. 2004. Etnomatemáticas: sobre a pluralidade nas significacoes do programa etnomatemática. En: Machado, J.; Santos, M. Ferreira, R. (eds). Etnomatemática: Papel, valor e significado. Ed. Zouk (Sao Paulo). p.75-87.

17. MACHADO, J.; SANTOS, M.; FERREIRA, R. 2004. Etnomatemática: Papel, valor e significado. Zouk. (San Pablo). 287p.

18. PALACIOS, J. 1989. Nueva Historia de Colombia Vol. 1. La esclavitud y la sociedad esclavista. Ed. Planeta Colombiana Editorial. p.168-170.

19. REY, M.; AROCA, A. 2011. Medición y estimación de los albañiles, un aporte a la educación matemática. Rev. U.D.C.A. Act. \& Div. Cient. 14(1):137-147.

Recibido. Enero 15 de 2012

Aceptado: Agosto 28 de 2012 